\title{
As hepatites virais: aspectos epidemiológicos, clínicos e de prevenção em municípios da Microrregião de Parauapebas, sudeste do estado do Pará, Brasil
}

\author{
Viral hepatitis: epidemiological, clinical aspects and prevention in municipalities of \\ the Parauapebas Microregion, southeastern Pará State, Brazil
}

Heloisa Marceliano Nunes, Vânia Pinto Sarmento, Andreza Pinheiro Malheiros, José Fábio da Paixão, Ocinéa do Socorro Gomes da Costa, Manoel do Carmo Pereira Soares

Instituto Evandro Chagas/SVS/MS, Seção de Hepatologia, Belém, Pará, Brasil

\begin{abstract}
RESUMO
INTRODUÇÃO: Curionópolis e Canaã dos Carajás são municípios localizados a sudeste do estado do Pará, Brasil, estando submetidos a grande fluxo migratório, pela influência de áreas de garimpo e pela implantação de grandes projetos de mineração, o que impõe a necessidade de se conhecer, na região, os padrões epidemiológicos de doenças endêmicas, como as hepatites virais. OBJETIVOS: Definir a frequência das infecções pelos vírus das hepatites $\mathrm{A}(\mathrm{VHA}), \mathrm{B}(\mathrm{VHB}), \mathrm{C}(\mathrm{VHC})$ e D (VHD) em amostras de soro de indivíduos procedentes de municípios da Microrregião de Parauapebas. MATERIAIS E MÉTODOS: Realizou-se estudo descritivo quantitativo, entre agosto de 2012 e setembro de 2014, utilizando dados coletados, de forma aleatória, de indivíduos dos municípios de Canaã dos Carajás e Curionópolis. Foram coletadas amostras de sangue para exames sorológicos das hepatites virais $A, B, C$ e $D$, por técnica imunoenzimática. RESULTADOS: Em Canaã dos Carajás, entre as 825 amostras, houve prevalência de $76,4 \%$ para anti-VHA; $0,2 \%$ eram $\mathrm{HBsAg}+$; foi detectada prevalência de $0,1 \%$ anti-VHC; sendo que $\mathrm{O}$ anti-HD das amostras $\mathrm{HBsAg}+$ foi negativo. Em Curionópolis, entre as 376 amostras de soro, a prevalência de anti-VHA foi de 84,8\%; 0,5\% apresentaram $\mathrm{HBsAg}+$; houve prevalência de anti-VHC de 0,5\%; e nenhuma amostra foi positiva para anti-HD. CONCLUSÃO: Concluiu-se, laboratorialmente, que Curionópolis apresentou endemicidade elevada para $\circ \mathrm{VHA}$ e $\odot \mathrm{VHB}$, e baixa para $\circ \mathrm{VHC}$; Canaã dos Carajás apresentou endemicidade elevada para $\circ \mathrm{VHA}$, intermediária para $\circ \mathrm{VHB}$ e baixa para $\circ \mathrm{VHC}$. $\mathrm{O} \mathrm{VHD}$ não foi encontrado nessas populações.
\end{abstract}

Palavras-chave: Hepatite A; Hepatite B; Hepatite C; Hepatite D.

\begin{abstract}
INTRODUCTION: Curionópolis and Canaã dos Carajás are municipalities located at southeast of Pará State, Brazil, with great migration flow due to the influence of mining areas and the implementation of large mining projects, making necessary to know the epidemiological patterns of endemic diseases in that region, such as viral hepatitis. OBJECTIVES: To define the incidence of hepatitis A (HAV), B (HBV), C (HCV) and D (HDV) virus infections in serum samples of people from municipalities in Parauapebas Microregion. MATERIALS AND METHODS: A quantitative and descriptive study was conducted between August 2012 and September 2014, using data collected randomly from individuals in Canaã dos Carajás and Curionópolis. Blood samples were collected for serological tests of viral hepatitis A, B, C and D by immunoenzymatic technique. RESULTS: In Canaã dos Carajás, among the 825 samples, there was a prevalence of $76.4 \%$ for anti-HAV; $0.2 \%$ were $\mathrm{HBsAg}+$; prevalence of $0.1 \%$ anti-HCV was detected; and anti-HD of the HBsAg + samples was negative. In Curionópolis, among the 376 serum samples, anti-HAV prevalence was $84.8 \%$; $0.5 \%$ showed $\mathrm{HBsAg}+$; there was anti-HCV prevalence of $0.5 \%$; and no samples were positive for anti-HD. CONCLUSION: It was concluded in laboratory that Curionópolis presented high endemicity for HAV and HBV and low for HCV; Canaã dos Carajás presented high HAV endemicity, HBV intermediate endemicity, and low for HCV. HDV was not found in those populations.
\end{abstract}

Keywords: Hepatitis A; Hepatitis B; Hepatitis C; Hepatitis D.

\footnotetext{
Correspondência / Correspondence:

Heloisa Marceliano Nunes

Instituto Evandro Chagas/SVS/MS, Seção de Hepatologia

Av. Almirante Barroso, 492. Bairro: Marco - CEP: 66093-020 - Belém, Pará, Brasil - Tel.: +55 (91) $3214-2131$

E-mail: heloisanunes@iec.pa.gov.br
} 


\section{INTRODUÇÃO}

As infecções pelos vírus das hepatites, causadas por agentes hepatotrópicos primários, podem evoluir de forma aguda (até mesmo fulminante) ou crônica, de forma sintomática ou assintomática, dependendo do agente viral envolvido e de fatores imunogenéticos do paciente. Atualmente, são conhecidos cinco vírus responsáveis pelas diferentes hepatites humanas: os vírus das hepatites A (VHA), B (VHB), C (VHC), D $(\mathrm{VHD})$ e $E(\mathrm{VHE})$, que pertencem, respectivamente, às famílias Picornaviridae, Hepadnaviridae, Flaviviridae, Deltaviridae e Hepeviridae?

De distribuição mundial, as hepatites virais $A, B$, $C$ e $D$ variam de frequência conforme a etiologia e as regiões geográficas. A hepatite $A$ tem incidência pouco conhecida, devido à maioria das infecções serem oligossintomáticas ou assintomáticas. De acordo com informações da Organização Mundial da Saúde², existem aproximadamente 2 bilhões de pessoas infectadas pelo VHB mundialmente; entre elas, 350 milhões são portadoras crônicas do vírus, sendo que a infecção pelo VHB representa a décima causa de morte em todo o mundo, resultando em 1 a 2 milhões de óbitos por ano. Existindo cerca de 150 a 170 milhões de infectados no mundo pelo VHC, no Brasil estima-se a presença de 3 a 4 milhões de portadores crônicos desse vírus ${ }^{1,3}$. A infecção pelo VHD ocorre em áreas endêmicas de hepatite $B$; calcula-se que existam 18 milhões de pessoas infectadas também em âmbito mundial. As taxas de mortalidade das hepatites virais agudas na Região Norte são as mais altas do país (de duas a cinco vezes maiores que a média brasileira) ${ }^{4}$.

A Microrregião de Paravapebas, localizada na Mesorregião do Sudeste Paraense, no estado do Pará, formada pelos municípios de Canaã dos Carajás, Água Azul do Norte, Curionópolis, Eldorado do Carajás e Parauapebas, junto com a Microrregião de Marabá, é o primeiro grande núcleo urbano atravessado pela ferrovia que transporta os minérios de Carajás ao porto de Itaqui, no estado do Maranhão, e vem sendo submetida a intenso fluxo migratório nos últimos anos, sob a influência das suas áreas de garimpo e da implantação de projetos de exploração de minérios ${ }^{5}$.

município de Curionópolis apresentava população estimada de 17.844 habitantes em 2014. Pela ocorrência de ouro em Serra Pelada, na década de 1980, consolidou-se como núcleo de apoio aos garimpeiros e de residência para seus familiares, que não podiam, à época, ingressar na área de garimpo, desenvolvendo-se, dessa forma, uma comunidade de comércio e setor de serviços diversificados, consolidando Curionópolis como povoação definitiva, mesmo após o escasseamento do ouro na região ${ }^{5}$.

- município de Canaã dos Carajás, com população estimada de 32.366 habitantes em 2014, é um município com expressiva indústria de extração mineral. Originou-se a partir do Projeto de Assentamento Carajás, em 1982, pelo Grupo Executivo das Terras do Araguaia e Tocantins (GETAT), do Governo Federal, para abrandar os conflitos pela posse de terra na região, particularmente na área conhecida como Bico do Papagaio. Por três anos, foram assentadas 1.551 famílias em área conhecida como Centro de Desenvolvimento Regional (Cedere). Após a extinção do GETAT, o Cedere foi desmembrado do município de Parauapebas, transformando-se no município de Canaã dos Carajás, cuja economia baseia-se na extração mineral, sendo a extração de cobre seu principal agente de desenvolvimento econômico. A exploração do cobre produziu grande migração populacional para Canaã dos Carajás, motivada pela busca de trabalho. Por esse motivo, houve uma explosão populacional - de aproximadamente 6.000 habitantes em 2000, a população passou para cerca de 25.000 em $2003^{5}$

Como são áreas submetidas a mudanças, inclusive as de influência dos projetos de mineração, impõe-se a necessidade de conhecimento de padrões epidemiológicos atuais de determinadas doenças endêmicas na região, como é o caso das hepatites virais, padrões esses necessários para avaliar as transformações decorrentes desse fluxo migratório.

Considerando as condições socioeconômicas e ecológicas da Amazônia, onde a escassez de recursos assistenciais adiciona-se às distâncias e à coexistência de várias doenças infecciosas na mesma área e ao mesmo tempo, a abordagem, com o auxílio de métodos laboratoriais, mais a capacidade instalada da Seção de Hepatologia (SAHEP), do Instituto Evandro Chagas (IEC), da Secretaria de Vigilância em Saúde (SVS) do Ministério da Saúde (MS), favoreceu que fosse traçado o perfil sorológico das infecções por VHA, VHB, VHC e VHD em Canaã dos Carajás e Curionópolis.

$\bigcirc$ estudo objetivou definir a frequência de marcadores das infecções por VHA, VHB, VHC e VHD em amostras de soro de indivíduos, procedentes dos municípios de Canaã dos Carajás e Curionópolis, recebidas na SAHEP/IEC; de forma específica, determinar a soroprevalência de infecções por esses vírus de amostras procedentes desses municípios; levantar a frequência de portadores das infecções por VHB, VHC e VHD; e, avaliar a resposta vacinal contra o $\mathrm{VHB}$.

\section{MATERIAIS E MÉTODOS}

Estudo descritivo exploratório quantitativo, realizado nos laboratórios de sorologia e biologia molecular da SAHEP/IEC em Belém, Pará, Brasil, no período de agosto de 2012 a setembro de 2014, utilizando dados e amostras de sangue coletados, de forma aleatória, de indivíduos dos municípios de Canaã dos Carajás e Curionópolis, os quais, sensibilizados pelo conhecimento da ocorrência da pesquisa, manifestaram vontade de participar do estudo.

Os dados epidemiológicos foram obtidos por meio de ficha de inquérito individual. Foram coletados, por meio de punção venosa, cerca de $8 \mathrm{~mL}$ de sangue 
dos adultos e $5 \mathrm{~mL}$ das crianças que participaram da pesquisa, para exames sorológicos das hepatites virais. O material, identificado numérica e nominalmente, foi colocado em tubo de ensaio por 1 a $3 \mathrm{~h} \mathrm{em}$ repouso, em temperatura ambiente, para retração do coágulo, e centrifugado por 15 min, a 3.000 G rotações por minuto. $\bigcirc$ soro obtido foi acondicionado em criotubos e refrigerado até seu transporte à SAHEP/IEC.

$\mathrm{Na}$ SAHEP, foram realizados, por técnica imunoenzimática, testes dos marcadores sorológicos do VHA (anti-VHA total; e, nas amostras de menores de 10 anos de idade, foi realizado o anti-VHA $\lg M)$, VHB (HBsAg, anti-HBc total, anti-HBs), VHC (anti-VHC) e VHD (anti-HD nas amostras HBsAg positivas), utilizando-se kits comerciais dos laboratórios Symbiosys ${ }^{\circledR}$, bioMérieux ${ }^{\circledR}, \quad$ ORTHO ${ }^{\circledR}$ e bioMérieux ${ }^{\circledR}$, respectivamente. $\bigcirc$ excedente das amostras foi congelado em freezer a $-70{ }^{\circ} \mathrm{C}$, ficando sob responsabilidade do IEC. Nas amostras anti-VHC positivo, foram efetuadas pesquisas para detecção do VHC-RNA por reação em cadeia da polimerase via transcriptase reversa (RT-PCR). Foram obedecidas as recomendações do fabricante em todos os testes, considerando-se duvidosos os resultados quando a densidade óptica se situou entre $20 \%$ para cima ou para baixo do limite de cut-off.

Tanto os resultados sorológicos como os dados das fichas de inquérito foram armazenados em base de dados da SAHEP/IEC (Hepatoware). Foi determinada a distribuição espacial dos casos detectados, com base em medidas epidemiológicas, incluindo-se o cálculo de frequência para casos prevalentes e sua relação com as variáveis demográficas.

Os resultados dos exames foram disponibilizados aos participantes da pesquisa, permitindo a adoção de medidas preventivas e de encaminhamento ao tratamento, se necessário, de acordo com o preconizado pelo Sistema de Vigilância e o Departamento de DST, Aids e Hepatites Virais da SVS/MS.

Com base na Resolução CNS n 196/1996, atualmente $n^{\circ}$ 466/2012, de junho de 2013, da Comissão Nacional de Ética em Pesquisa ${ }^{6}$, o projeto foi aprovado em 14 de dezembro de 2010, pelo Comitê de Ética em Pesquisa Envolvendo Seres Humanos do IEC, com Parecer de Aprovação n 040/2010 (CAAE: 0002.0.072.000-09).

\section{RESULTADOS}

\section{ESTUDO TRANSVERSAL NO MUNICÍPIO DE CANAÃ DOS CARAJÁS}

Entre agosto de 2012 e setembro de 2014, foram coletadas amostras de sangue de 825 indivíduos de Canaã dos Carajás. Entre os participantes da pesquisa, observou-se uma frequência de 53,3\% (440/825) para indivíduos do sexo feminino e de 46,7\% (385/825) para o masculino. Foi encontrada média de idade de $28,7 \pm 19,7$ anos (variação de 7 meses a 86 anos) e mediana, de 25 anos. A maior concentração de participantes estava na faixa de 10 a 19 anos $(24,4 \%$; $201 / 825)$ e a menos frequente entre os menores de 1 ano de idade $(0,1 \%$; 1/825).

estudo detectou prevalência global de 76,4\% (630/825) para o anti-VHA totalt, com 23,6\% (195/825) suscetíveis ao VHA. Em 31,2\% (43/138) de amostras de participantes na faixa etária entre menores de 1 e 9 anos, foram realizadas sorologias anti-VHA IgM onde foi encontrado 1,1\% (1/89) de positividade na faixa etária de 5 a 9 anos (Tabela 1).

Tabela 1 - Frequência de anti-VHA total+ e anti-VHA lgM+ por faixa etária, no município de Canaã dos Carajás, estado do Pará, Brasil, de agosto de 2012 a setembro de 2014

\begin{tabular}{|c|c|c|c|c|c|}
\hline \multirow{2}{*}{$\begin{array}{l}\text { Faixa etária } \\
\text { (anos) }\end{array}$} & \multirow{2}{*}{$\begin{array}{c}\text { Total } \\
\text { examinado }\end{array}$} & \multicolumn{2}{|c|}{ Anti-VHA total+ } & \multicolumn{2}{|c|}{ Anti-VHA lgM+ } \\
\hline & & $\mathrm{N}$ & $\%$ & $\mathrm{~N}$ & $\%$ \\
\hline$<1$ & 1 & - & - & - & - \\
\hline $1-4$ & 48 & 11 & 22,9 & - & - \\
\hline 5-9 & 89 & 32 & 36,0 & 1 & 1,1 \\
\hline 19-10 & 201 & 130 & 64,7 & - & - \\
\hline 20-29 & 119 & 107 & 89,9 & - & - \\
\hline 30-39 & 119 & 111 & 93,3 & - & - \\
\hline 40-49 & 106 & 103 & 97,2 & - & - \\
\hline 50-59 & 69 & 67 & 97,1 & - & - \\
\hline $60>$ & 72 & 69 & 95,8 & - & - \\
\hline $\begin{array}{c}\text { Sem } \\
\text { informação }\end{array}$ & 1 & - & - & - & - \\
\hline Total & 825 & 630 & 76,4 & 1 & 0,1 \\
\hline
\end{tabular}

Sinal convencional utilizado: - Dado numérico igual a zero, não resultante de arredondamento.

Quanto à hepatite $B$, detectou-se prevalência total de $55,9 \%$ (461/825) para algum marcador do VHB, com 44,1\% (364/825) suscetíveis; 0,2\% (2/825) eram portadores do VHB; 12,1\% (100/825) apresentaram perfil de infecção pregressa pelo $\mathrm{VHB} ; 1,7 \%$ (14/825) tinham perfil compatível com infecção pregressa ou atual pelo $\mathrm{VHB} ; 41,8 \% \quad(345 / 825)$ apresentaram resposta vacinal contra $\bigcirc \mathrm{VHB}$; e o perfil sorológico vacinal até 10 anos de idade se mostrou em 62,3\% (86/138), conforme apresentado na tabela 2 .

Entre as amostras $\mathrm{HBsAg}+$, a pesquisa do marcador sorológico anti-HD se mostrou negativa. $\bigcirc$ estudo detectou prevalência de anti-VHC+ de 0,1\% (1/825), em indivíduo do sexo masculino, com 49 anos de idade, confirmado por RT-PCR como portador do VHC, genótipo 1 . 
Tabela 2 - Prevalência de HBsAg+, anti-HBc total+/anti-HBs+, anti-HBc+ isolado e anti-HBs+ isolado, por faixa etária, no município de Canaã dos Carajás, estado do Pará, Brasil, de agosto 2012 a setembro 2014

\begin{tabular}{|c|c|c|c|c|c|c|c|c|c|}
\hline \multirow{2}{*}{$\begin{array}{l}\text { Faixa etária } \\
\text { (anos) }\end{array}$} & \multirow{2}{*}{$\begin{array}{c}\text { Total } \\
\text { examinado }\end{array}$} & \multicolumn{2}{|c|}{$\mathrm{HBsAg}+$} & \multicolumn{2}{|c|}{ Anti-HBc+/anti-HBs+ } & \multicolumn{2}{|c|}{ Anti-HBs+isolado } & \multicolumn{2}{|c|}{ Anti-HBc+isolado } \\
\hline & & N & $\%$ & $\mathrm{~N}$ & $\%$ & $\mathrm{~N}$ & $\%$ & N & $\%$ \\
\hline$<1$ & 1 & - & - & - & - & - & - & - & - \\
\hline $1-4$ & 48 & - & - & - & - & 34 & 70,8 & 1 & 2,1 \\
\hline $5-9$ & 89 & - & - & - & - & 52 & 58,4 & - & - \\
\hline $10-19$ & 201 & - & - & 3 & 1,5 & 97 & 48,3 & 2 & 1,0 \\
\hline 20-29 & 119 & - & - & 8 & 6,7 & 68 & 57,1 & - & - \\
\hline 30-39 & 119 & - & - & 14 & 11,8 & 44 & 37,0 & 2 & 1,7 \\
\hline $40-49$ & 106 & 1 & 0,9 & 30 & 28,3 & 28 & 26,4 & 5 & 4,7 \\
\hline $50-59$ & 69 & 1 & 1,4 & 20 & 29,0 & 12 & 17,4 & 1 & 1,4 \\
\hline $60>$ & 72 & - & - & 25 & 34,7 & 10 & 13,9 & 3 & 4,2 \\
\hline Sem informação & 1 & - & - & - & - & - & - & - & - \\
\hline Total & 825 & 2 & 0,2 & 100 & 12,1 & 345 & 41,8 & 14 & 1,7 \\
\hline
\end{tabular}

$\mathrm{HBsAg}+$ : Portador do VHB; Anti-HBc+ / anti-HBs +: Perfil de infecção pregressa pelo VHB; Anti-HBs + isolado: Perfil compatível com proteção vacinal; Anti-HBc+ isolado: Perfil compatível com infecção pregressa ou atual pelo VHB; Sinal convencional utilizado: - Dado numérico igual a zero, não resultante de arredondamento.

\section{ESTUDO TRANSVERSAL NO MUNICÍPIO DE CURIONÓPOLIS}

No período de 16 a 29 de janeiro de 2013, foram coletadas amostras de sangue de 376 indivíduos de Curionópolis. Observou-se uma frequência de $51,9 \%(195 / 376)$ para indivíduos do sexo masculino e de $48,1 \%(181 / 376)$ para o feminino. A média de idade da população foi de 37,2 \pm 24 anos (variação de 5 meses a 99 anos) e a mediana, de 35 anos. As maiores concentrações de participantes foram encontradas nas faixas de 10 a 19 anos $(22,6 \%$; $85 / 376)$ e de maiores de 60 anos $(21,8 \% ; 82 / 376)$. A faixa etária menos frequente foi a de menores de 1 ano $(0,3 \% ; 1 / 376)$, conforme a tabela 3 .

Tabela 3 - Frequência de anti-VHA totalt por faixa etária, no município de Curionópolis, estado do Pará, Brasil, em janeiro de 2013

\begin{tabular}{cccc}
\hline $\begin{array}{c}\text { Faixa etária } \\
\text { (anos) }\end{array}$ & $\begin{array}{c}\text { Total } \\
\text { examinado }\end{array}$ & \multicolumn{2}{c}{ Anti-VHA total +} \\
\hline$<1$ & 1 & 1 & 100,0 \\
$1-4$ & 23 & 10 & 43,5 \\
$5-9$ & 23 & 10 & 43,5 \\
$10-19$ & 85 & 64 & 75,3 \\
$20-29$ & 33 & 29 & 87,9 \\
$30-39$ & 37 & 36 & 97,3 \\
$40-49$ & 35 & 33 & 94,3 \\
$50-59$ & 57 & 56 & 98,2 \\
$60>$ & 82 & 80 & 97,6 \\
\hline Total & 376 & 319 & 84,8 \\
\hline
\end{tabular}

O estudo detectou prevalência global de $84,8 \%$ $(319 / 376)$ para 0 anti-VHA totalt, com 15,2\% (57/376) suscetíveis ao VHA. Em 44,7\% (21/47) das amostras de participantes, na faixa etária entre menores de 1 e 9 anos, foram realizadas sorologias anti-VHA IgM, com resultados negativos em todas as amostras examinadas (Tabela 3).

Em relação à hepatite $B$, detectou-se prevalência total de $63,6 \%(239 / 376)$ para algum marcador do $\mathrm{VHB}$, com 36,4\% (137/376) suscetíveis ao vírus; $0,5 \%$ (2/376) apresentaram $\mathrm{HBsAg}+; 20,2 \%$ (76/376) anti-HBc total+/anti-HBs+; e 3,5\% (13/376) anti-HBc+ isolado. Entre os examinados, 39,4\% (148/376) demonstraram resposta vacinal contra o VHB (anti-HBs + isolado), e o perfil sorológico vacinal, até os 10 anos de idade, mostrou-se em 68,1\% (32/47), conforme apresentado na tabela 4.

Entre as amostras $\mathrm{HBsAg}+$, a pesquisa do marcador sorológico anti-HD se mostrou negativa. Nesse município, detectou-se prevalência de anti-VHC+ de 0,5\% (2/376). Entre os anti-VHC+, houve a confirmação por RT-PCR de portadores do VHC, genótipo 1, de dois indivíduos: um do sexo masculino, com 57 anos de idade; e outro do feminino, com 48 anos.

\section{DISCUSSÃO}

Segundo Hadler e Margolis7, existem cinco padrões soroepidemiológicos de infecção pelo VHA em todo o mundo: áreas de muito alta, alta, intermediária, baixa e muito baixa endemicidade. Um estudo realizado a respeito da hepatite A na Amazônia brasileira encontrou soroprevalência de $92,8 \%$, maior que a média nacional encontrada em 2000, que era de 64,7\%, classificando a Região Norte como área de alta endemicidade para $\circ \mathrm{VHA}$. 
Tabela 4 - Prevalência de HBsAg +, anti-HBc total +/anti-HBs +, anti-HBc+ isolado e anti-HBs+ isolado, por faixa etária, no município de Curionópolis, estado do Pará, Brasil, janeiro 2013

\begin{tabular}{|c|c|c|c|c|c|c|c|c|c|}
\hline \multirow{2}{*}{$\begin{array}{l}\text { Faixa etária } \\
\text { (anos) }\end{array}$} & \multirow{2}{*}{$\begin{array}{c}\text { Total } \\
\text { examinado }\end{array}$} & \multicolumn{2}{|c|}{$\mathrm{HBsAg}+$} & \multicolumn{2}{|c|}{ Anti-HBc+/anti-HBs +} & \multicolumn{2}{|c|}{ Anti-HBc+isolado } & \multicolumn{2}{|c|}{ Anti-HBs + isolado } \\
\hline & & N & $\%$ & $N$ & $\%$ & $\mathrm{~N}$ & $\%$ & N & $\%$ \\
\hline$<1$ & 1 & - & - & - & - & - & - & - & - \\
\hline $1-4$ & 23 & & - & - & - & - & - & 16 & 69,6 \\
\hline $5-9$ & 23 & & - & - & - & - & - & 16 & 69,6 \\
\hline 10-19 & 85 & & - & - & - & 1 & 1,2 & 51 & 60,0 \\
\hline $20-29$ & 33 & & - & 2 & 6,1 & 1 & 3,0 & 18 & 54,5 \\
\hline $30-39$ & 37 & & - & 7 & 18,9 & - & - & 17 & 45,9 \\
\hline $40-49$ & 35 & & - & 4 & 11,4 & 1 & 2,9 & 7 & 20,0 \\
\hline $50-59$ & 57 & 2 & 3,5 & 23 & 40,4 & 4 & 7,0 & 8 & 14,0 \\
\hline $60>$ & 82 & - & - & 40 & 48,8 & 6 & 7,3 & 15 & 18,3 \\
\hline Total & 376 & 2 & 0,5 & 76 & 20,2 & 13 & 3,5 & 148 & 39,4 \\
\hline
\end{tabular}

$\mathrm{HBsAg}+$ : Portador do VHB; Anti-HBc+/ anti-HBs + : Perfil de infecção pregressa pelo VHB; Anti-HBs + isolado: Perfil compatível com proteção vacinal; Anti-HBc+ isolado: Perfil compatível com infecção pregressa ou atual pelo VHB; Sinal convencional utilizado: - Dado numérico igual a zero, não resultante de arredondamento.

Um estudo que incluiu 26 capitais de cinco macrorregiões do Brasil e o Distrito Federal, realizado entre 2004 e 2009, com indivíduos na faixa etária de 5 a 19 anos, identificou prevalência para a exposição à infecção pelo VHA de $39,5 \%$, colocando o conjunto das capitais do Brasil, inclusive as capitais da Região Norte, como de endemicidade intermediária para - VHA. Esse estudo identificou associação direta entre idade e soropositividade para $\mathrm{O}$ anti-VHA e uma associação inversa entre soropositividade para o anti-VHA e as condições socioeconômicas dos indivíduos ${ }^{8,9}$.

Dados do MS informaram que, entre 2005 e 2014, houve um decréscimo no número de casos diagnosticados anualmente de hepatite $A$, que a maior concentração de casos encontrava-se na faixa de 5 a 6 anos de idade, e que as Regiões Norte e Nordeste foram as responsáveis pelo maior número de $\operatorname{casos}^{10}$.

No estado do Pará, foram notificados e confirmados, no Sistema de Informação de Agravos de Notificação (Sinan), em 2015, 806 casos de hepatites virais, dos quais $43,9 \%$ foram classificados etiologicamente como hepatite $A$, sendo que, entre os casos notificados de hepatite A no Pará, 2,4\% estavam na Região de Saúde de Carajás ${ }^{11}$.

As soroprevalências de $76,4 \%$ e de $84,8 \%$ para anti-VHA total+ encontradas em Canaã dos Carajás e Curionópolis, respectivamente, classificaram esses municípios como de alta endemicidade para o VHA.

$\bigcirc$ estudo que envolveu as capitais brasileiras, incluindo o Distrito Federal, realizado entre 2004 e 2009, apresentou resultado global da prevalência para o marcador de infecção do VHB (anti-HBc) de $7,4 \%$ e prevalência de HBsAg de $0,4 \%$, classificando - conjunto das capitais brasileiras como de baixa endemicidade para $\circ \mathrm{VHB}$. A prevalência de anti-HBc, referente ao conjunto das capitais da Região Norte, foi de $10,9 \%$ e de $0,6 \%$ para $\circ \mathrm{HBs} A g$, classificando - conjunto das capitais do Norte como de baixa endemicidade para $\circ \mathrm{VHB}^{8,9}$.

Segundo o Boletim Epidemiológico do $\mathrm{MS}^{10}$, entre 2005 e 2014, observou-se que não houve mudanças significativas quanto à notificação de casos de hepatite B, que a faixa etária mais acometida encontrava-se entre 20 e 40 anos, e que as regiões Sul e Sudeste apresentaram o maior número de casos diagnosticados, provavelmente devido a um melhor sistema de vigilância epidemiológica.

Entre os 806 casos de hepatites virais notificados e confirmados no Sinan, em 2015, no Pará, 33,5\% foram classificados como hepatite B; entre esses, 4,5\% estavam na Região de Saúde de Carajás ${ }^{11}$.

Um estudo de revisão da literatura sobre a distribuição da infecção pelo VHB no Brasil, realizado por Souto' ${ }^{2}$, indicou uma tendente redução da prevalência da hepatite $B$ em âmbito nacional, classificando o Brasil como sendo de baixa endemicidade para o VHB. Essa revisão também mostrou a necessidade de intensificar estratégias de vacinação para jovens e adultos em regiões mais isoladas, como a Região Amazônica, e em grupos específicos, a exemplo dos sem-teto em grandes cidades e das comunidades afrodescendentes.

Neste estudo, em Canaã dos Carajás, foi encontrada prevalência total de $55,9 \%$ de infecção pelo VHB na população pesquisada, mostrando padrão de endemicidade intermediária ${ }^{2,13,14}$. A presença de $0,2 \%$ de portadores do VHB na faixa etária entre 40 e 59 anos, a existência de $44,1 \%$ suscetíveis ao vírus, a resposta vacinal de $41,8 \%$, com perfil imunológico vacinal até 10 anos de idade de $62,3 \%$. Em Curionópolis, houve prevalência total de 63,6\% 
de infecção pelo VHB, mostrando padrão de alta endemicidade $2,13,14$, a presença de 0,5\% portadores do $\mathrm{VHB}$, com HBsAg + na faixa etária entre 50 a 59 anos, a existência de $36,4 \%$ de suscetíveis ao vírus, resposta vacinal de 39,4\%, com perfil imunológico vacinal até 10 anos de idade de 68,1\%. Esses resultados revelaram que medidas de controle da infecção vêm sendo desenvolvidas, mas que é preciso intensificar a vacinação contra a hepatite $B$ nos municípios. A vacina está disponível para todos os indivíduos, nas salas de vacinação do Sistema Único de Saúde, independentemente de idade ou de condições de vulnerabilidade, conforme Nota Informativa $n^{\circ}$ 149/2015/CGPNI/DEVIT/SVS/MS ${ }^{15}$.

$\bigcirc$ resultado global da prevalência para o marcador anti-VHC das capitais brasileiras foi de 1,38\%, classificando o conjunto de capitais do Brasil como de baixa endemicidade para o $\mathrm{VHC}$. $\bigcirc$ conjunto das capitais da Região Norte mostrou prevalência de 2,1\%, mais elevada que a de outras regiões do país ${ }^{8,9}$.

Do total de casos de hepatite $C$ notificados ao Sinan, entre 2004 e 2014, não houve alterações significativas, à exceção do ano de 2013, quando foi detectada uma elevação de 49,0\% em relação à média do período. A faixa etária mais acometida encontrava-se entre 40 e 65 anos, e as Regiões Sul e Sudeste responderam por cerca de $86,0 \%$ dos casos, sendo que somente a Região Sudeste foi responsável pela notificação de aproximadamente $60,0 \%$ dos casos no Brasil ${ }^{10}$.

Entre os 806 casos de hepatites virais notificados e confirmados no Sinan, em 2015, no Pará, 17,4\% foram classificados como hepatite $C$; entre esses, apenas 0,6\% estava na Região de Saúde de Carajás $^{11}$.

As soroprevalências de $0,1 \%$ e de $0,5 \%$ de anti-VHC+, encontradas em Canaã dos Carajás e em Curionópolis, respectivamente, classificaram esses municípios como de baixa endemicidade para o VHC. Nas amostras anti-VHC+, foram confirmados por RT-PCR indivíduos portadores do VHC, todos genótipo 1, reforçando que é preciso estar atento para o controle da infecção, sendo necessário desenvolver, nesses municípios, atividades visando ampliar as medidas de controle e prevenção.

A não detecção de portadores do VHD, nas amostras $\mathrm{HBsAg}+$ nos estudos, indicou, por se tratar de um vírus defectivo, a necessidade também da presença do VHB para se tornar infectante. A vacinação em massa contra a hepatite $B$ constitui-se na maneira mais eficaz de redução da prevalência e incidência da infecção pelo VHD nos casos de coinfecção VHB e VHD, o mesmo não se aplicando aos casos de superinfecção? ${ }^{1}$.

\section{CONCLUSÃO}

estudo realizado em Canaã dos Carajás caracterizou laboratorialmente alta prevalência de infecção pelo $\mathrm{VHA}$; indicou a presença de portadores crônicos e de suscetíveis para o $\mathrm{VHB}$ e insuficiente cobertura vacinal contra o VHB; identificou um portador do VHC, genótipo 1; e não constatou a ocorrência de indivíduos portadores do VHD. Além disso, foi possível classificar o Município como de alta endemicidade para o VHA; de intermediária endemicidade para o $\mathrm{VHB}$; e de baixa endemicidade para VHC e VHD.

Em Curionópolis, a caracterização laboratorial mostrou alta prevalência de infecção pelo VHA; detecção de portadores crônicos e de suscetíveis ao $\mathrm{VHB}$ e ainda baixa cobertura vacinal contra esse vírus; presença de portadores do $\mathrm{VHC}$, com genótipo 1 ; e ausência de infectados pelo VHD. Concluiu-se que esse Município era de alta endemicidade para VHA e VHB e de baixa endemicidade para VHC e VHD.

Os resultados encontrados para a infecção pelo VHA, em ambos os municípios, são um reflexo das condições sanitárias e de higiene desfavoráveis, evidenciando a necessidade de desenvolver ou aprimorar atividades de saneamento básico e de controle de dejetos e do lixo, disponibilizar água potável à população, implementar ações educativas e de esclarecimentos à comunidade sobre a doença e formas de prevenção, assim como ampliar as atividades da vigilância epidemiológica, melhorando as ações de notificação, investigação de casos/ surtos e encerramento de casos. Propõe-se que a Vacina Adsorvida Hepatite A (inativada) purificada, disponibilizada pelo Programa Nacional de Imunização do MS, a partir de 2014, seja implantada, levando-se em consideração o elevado número de suscetíveis entre os menores de 4 anos de idade detectado nos municípios.

Em relação ao $\mathrm{VHB}$, o grande número de suscetíveis revelado pelo estudo apontou a necessidade de intensificar a vacinação contra a hepatite $B$ nos municípios, considerando o intenso fluxo migratório para a área de mineração, o que poderia proporcionar um aumento da transmissão do VHB. Reitera-se, portanto, a importância da vacinação contra o VHB como medida de controle e prevenção mais confiável, efetiva e de maior impacto contra o vírus.

Em virtude da detecção de infectados e portadores do VHC nos municípios estudados, associada à inexistência de medidas de prevenção, como a vacina ou a imunoglobulina, os meios mais adequados de proteção seriam: envolver atividades relacionadas à análise de sangue e hemoderivados, órgãos, tecidos e sêmen; medidas adequadas de esterilização de materiais de reuso; instituição de programas de aconselhamento para redução de riscos e danos; testagem de indivíduos em situação de risco; tratamento dos infectados; atividades educativas; e aprimoramento de medidas de prevenção da propagação da infecção.

A ausência de portadores do VHD e a presença de indivíduos infectados pelo VHB poderão propiciar, se medidas de vigilância epidemiológica não forem efetivadas nesses municípios, o surgimento da infecção pelo VHD, contribuindo para isso o elevado número de trabalhadores e de suas famílias que se deslocam para esses municípios, atraídos pelas ofertas de trabalho e de melhores condições de vida. 


\section{REFERÊNCIAS}

1 Ministério da Saúde (BR). Secretaria de Vigilância em Saúde. Guia de vigilância em saúde. Brasília: Ministério da Saúde; 2014. Hepatites virais; p. $311-24$.

2 World Health Organization. Vaccines and diseases: hepatitis B. Geneva: WHO; 2014.

3 World Health Organization. Hepatitis C [Internet]. Geneva: WHO; 2017 [cited 2017 Apr 17]. Available from: http://www.who.int/mediacentre/ factsheets/fs 164/en/.

4 Clemens SAC, Fonseca JC, Azevedo T, Cavalcante A, Silveira TR, Castilho MC, et al. Soroprevalência para hepatite $A$ e hepatite $B$ em quatro centros no Brasil. Rev Soc Bras Med Trop. 2000 jan-fev;33(1): 1-10.

5 Instituto Brasileiro de Geografia e Estatística. Censo demográfico 2010 [Internet]. Rio de Janeiro: IBGE; 2010 [citado 2015 mar 9]. Disponível em: www. cidades.ibge.gov.br/.

6 Brasil. Ministério da Saúde. Conselho Nacional de Saúde. Resolução $n^{\circ}$ 466, de 12 de junho de 2012. Aprova as diretrizes e normas regulamentadoras de pesquisas envolvendo seres humanos. Diário Oficial da União, Brasília (DF), 2013 jun 13; Seção 1:59.

7 Hadler SC, Margolis HS. Viral hepatitis. In: Evans AS, Kaslow RA, editors. Viral infections of humans: epidemiology and control. 3rd ed. New York: Plenun Medical Book; 1989. p. 351-91.

8 Ministério da Saúde (BR). Secretaria de Vigilância em Saúde. Estudo de prevalência de base populacional das infecções pelos vírus das hepatites $A, B$ e $C$ nas capitais do Brasil. Recife: Universidade de Pernambuco; 2010.
9 Ximenes RAA, Pereira LMB, Martelli CMT, MerchánHamann E, Stein AT, Figueiredo $G M$, et al. Methodology of a nationwide cross-sectional survey of prevalence and epidemiological patterns of hepatitis A, B and C infection in Brazil. Cad Saude Publica. 2010 Sep;26(9):1693-704.

10 Ministério da Saúde (BR). Secretaria de Vigilância em Saúde. Departamento de DST, Aids e Hepatites Virais. Bol Epidemiol Hepatites Virais. 2015;4(1):95.

11 Ministério da Saúde (BR). Departamento de Informática do SUS. Hepatites virais: casos confirmados notificados no Sistema de Informação de Agravos de Notificação, Pará [Internet]. Brasília: Ministério da Saúde; 2016 [citado 2016 set 16]. Disponível em: http://tabnet.datasus.gov.br/cgi/ tabcgi.exe? sinannet/cnv/hepabr.def.

12 Souto FJ. Distribution of hepatitis B infection in Brazil: the epidemiological situation at the beginning of the $21^{\text {st }}$ century. Rev Soc Bras Med Trop. 2016 Feb;49(1):11-23.

13 Souto FJD. Distribuição da hepatite B no Brasil: atualização do mapa epidemiológico e proposições para seu controle. GED Gastrointest Endosc Digest. 1999 jul-ago;1 8(4): 143-50.

14 Chen ST, Chang MH. Epidemiology and natural history of hepatitis B in children. In: Jonas MM, editor. Viral hepatitis in children: unique features and opportunities. New York: Springer; 2010. p. 13-28. (Clinical gastroenterology).

15 Ministério da Saúde (BR). Secretaria de Vigilância em Saúde. Departamento de Vigilância das Doenças Transmissíveis. Coordenação Geral do Programa Nacional de Imunizações. Nota Informativa $n^{\circ} 149$ de 2015/CGPNI/DEVIT/SVS/ MS. Informa as mudanças no Calendário Nacional de Vacinação para o ano de 2016. Brasília: Ministério da Saúde; 2015. 